\title{
OPTIMAL DESIGN AND ANALYSIS OF VEHICLE SUSPENSION SYSTEM
}

\section{LIKAJ, R.; SHALA, A.; BRUQI, M. \& BAJRAMI, XH.}

Abstract: The chapter deals with the optimal design and analysis of quarter car vehicle suspension system. For optimal designs are used the optimal parameters which have been derived by comparison of two optimisation algorithms: Sequential Quadratic Program (SQP) and Genetic Algorithms (GA's), for a five chosen design parameters. The goal function is chosen to provide the possibility to emphasize three main objectives of vehicle suspensions; ride comfort, suspension travel and road holding. Fuzzy Logic Control (FLC) is considered to control active suspension for the optimal parameters derived by GA's, and the rule base can be tuned to improve each of the above objectives, while the main focus is to minimise the vertical vehicle body acceleration. It also deals with parametric analysis, state space modelling, Laplace Transform, Transfer Function, Stability, Controllability, Observability and many other important attributes to analyse quarter car vehicle model.

Key words: Optimisation, parametric analysis, optimal control, GA, FLC
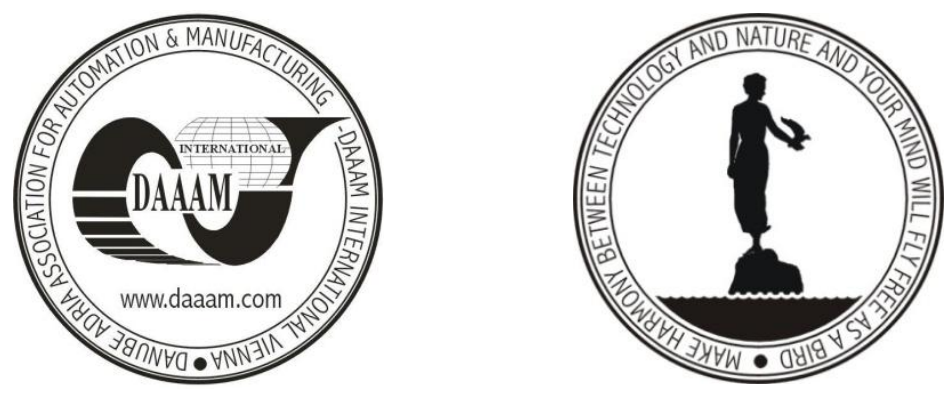

Authors' data: Univ. Prof. Dr. sc. Likaj, R[ame]*; Univ. Prof. Dr. sc. Shala, A[hmet]*; Univ. Prof. Dr. sc. Bruqi, M[irlind]*; Univ. Prof. Dr. sc. Bajrami, $\mathrm{Xh}[$ evahir]**, *University of Prishtina, Faculty of Mechanical Engineering, Bregu i diellit, P.N., 10000, Prishtina, Kosovo, ${ }^{*}$ University of Prizren, Faculty of Computer Science, 20000, Prizren, Kosovo,ramelikaj@gmail.com , ahmet.shala@uni-pr.edu, mirlind.bruqi@uni-pr.edu,xhbajrami@hotmail.com

This Publication has to be referred as: Likaj, R[ame]; Shala, A[hmet]; Bruqi, M[irlind] \& Bajrami, X[hevahir] (2014). Optimal Design and Analysis of Vehicle Suspension System, Chapter 07 in DAAAM International Scientific Book 2014, pp.087-108, B. Katalinic (Ed.), Published by DAAAM International, ISBN 978-3901509-98-8, ISSN 1726-9687, Vienna, Austria

DOI: $10.2507 /$ daaam.scibook.2014.07 
Likaj, R.; Shala, A.; Bruqi, M. \& Bajrami, X.: Optimal Design and Analysis of Veh...

\section{Introduction}

Nowadays the focus of vehicle suspension design has switched from pure numerical analysis to the application of different algorithms which are designed based on optimization methods. The development of optimizing methods is connected with the development of an automatic control of systems, which is the case in our study.

Algorithms designed based on optimizing methods enables us to fasten the search process of finding optimal solution expressed by an objective function under the fulfillment of constraint conditions, which evidently has a great influence on the development of the whole group of modern control methods that for the calculation of the control effect utilize a mathematical model of the process determined based on the measured process data (MPC methods and algorithms). At present, a great success has been achieved by agent and colonic control methods as well as methods and genetic algorithms used in the system of off-line techniques applied to the searching for a global extreme of a goal function. The applications of the mentioned methods and their algorithms to nonlinear processes modeling and control, systems, significantly contribute to the improvement of approximation properties of modeling processes as well as to the improvement of a control quality of selected types of a control (Jadlovska, et al., 2011).

Genetic algorithms (GAs) have been used in various applications such as function optimization, system identification and control systems. GAs is generalpurpose stochastic optimization methods for solving search problems to seek a global optimum. However, GAs is characterized by a large number of function evaluations (Likaj, et al., 2009).

On the other hand, traditional methods, such as sequential quadratic programming (SQP), are well known to exploit all local information in an efficient way, provided that certain conditions are met and the function to be minimized is 'well-conditioned' in the neighbourhood of a unique optimum. These methods require adequate local information to be known (such as the gradient and Hessian matrix). If the basic requirements are not satisfied, the reliability of the SQP method is greatly jeopardized.

The aim of this study is to find optimal design parameters, for quarter car model, by minimising a nonlinear objective function subjected to a set of constraints with two different optimisation algorithms; SQP and GA in order to improve ride quality. By means of the ride quality analysis in the frequency domain, the vertical vehicle body acceleration (VBA), suspension working space (SWS) and dynamic tire load (DTL) can be obtained (Likaj, et al., 2009).

In this design optimization, the main objective is to minimize the VBA acceleration. In the meantime, the SWS and DTL are constrained. If the SWS is too small, the sprung mass will strike the un-sprung mass and this may lead to damage of the vehicle. If the DTL is greater than the static tire load, the vehicle's tires will bounce off the road (Likaj, et al., 2002, 2003) and this will result in unstable modes of vehicle motion. Therefore, we aimed to present the development of a method for obtaining poles, eigenvectors, natural frequencies and mode shapes, in order to perform a vibration analysis for a quarter car model by using three different approaches (Likaj, et al., 2003, 2004, 2005) and comparison of the natural 
frequencies which have been obtained for the optimised model with the natural frequencies defined by the laws of the vibration theory. The parametric analysis gave information on how the natural frequency is affected when one of the parameters is perturbed. Parametric studies of dynamical systems are an important task in all major engineering design. This is especially true in the design of control systems. It is important to know when one parameter is changed, how that affects the system; if the system becomes unstable, do the natural frequencies change, etc. In addition we presented a task of state space modelling, Laplace Transformation, Transfer Function, Stability, Controllability, Observability as one of most important attributes to analyse quarter car vehicle model.

Another aim was to develop a Fuzzy Logic Controller (FLC) for a quarter car model with optimised parameters, with a rule base (Cai\& Konik, 1993, Likaj, et al., 2005), which can be tuned to improve each of three objectives; ride comfort, suspension working travel and handling.

In addition, in this study we have applied in integrative way software programs MATLAB and SIMULINK for optimisation, analysis, design and control of a quarter car model.

\section{Dynamical model of quarter car vehicle model}

The model of the quarter-car active suspension system used in this paper with two degree of freedom is shown in Fig. 1. The model represents a single wheel of a car in which the wheel is connected to the quarter portion of the car body through a hydro pneumatic suspension.

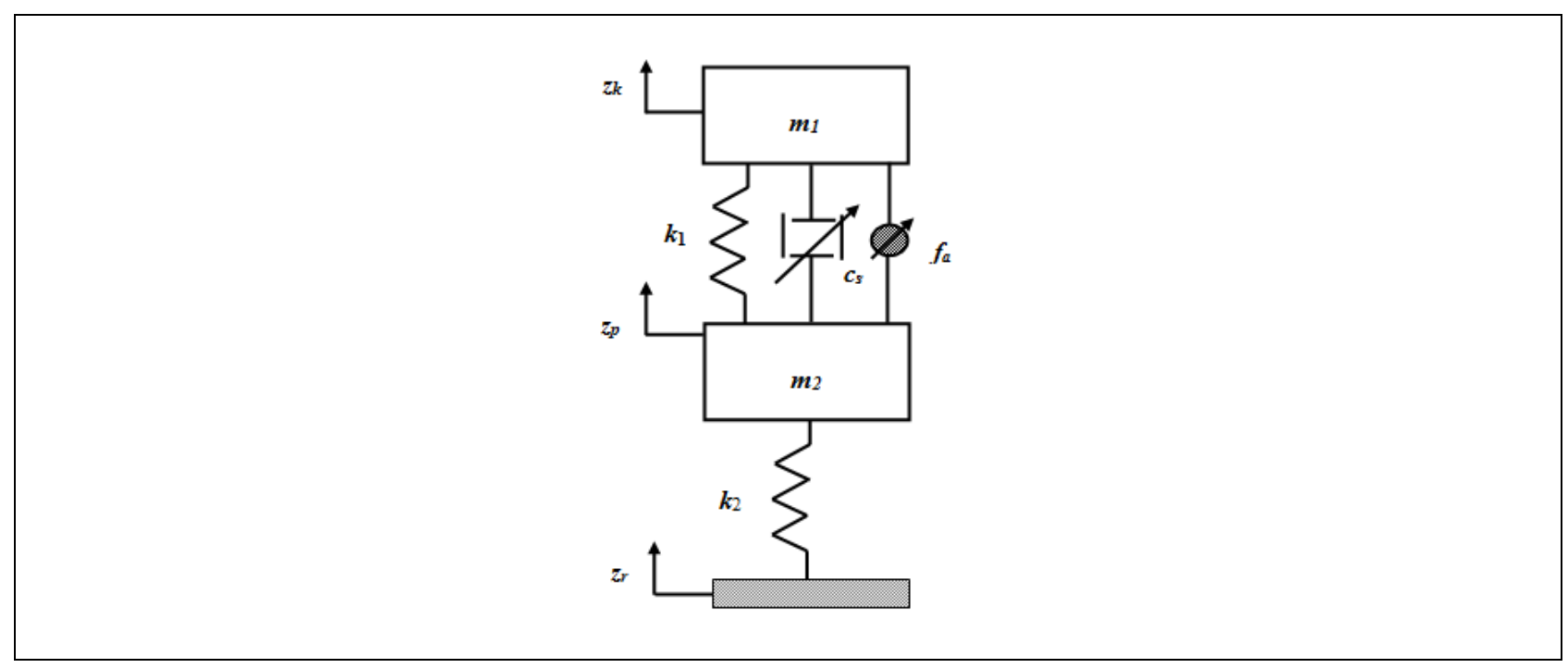

Fig. 1. Quarter car suspension model of $2 \mathrm{DOF}$

The dynamics of quarter car model in Fig. 1 are described by:

$$
\begin{aligned}
& m_{1} \ddot{z}_{k}=f_{a}-k_{1}\left(z_{k}-z_{p}\right)-c_{s}\left(\dot{z}_{p}-\dot{z}_{k}\right) \\
& m_{2} \ddot{z}_{p}=-f_{a}+k_{1}\left(z_{k}-z_{p}\right)+c_{s}\left(\dot{z}_{k}-\dot{z}_{p}\right)-k_{2}\left(z_{p}-z_{r}\right)
\end{aligned}
$$

The model parameters and their respective units are summarized in Tab. 1. 
Likaj, R.; Shala, A.; Bruqi, M. \& Bajrami, X.: Optimal Design and Analysis of Veh...

\begin{tabular}{|r|r|r|}
\hline Symbol & Description & Value \\
\hline$m_{1}$ & Body mass & $200 \mathrm{~kg}$ \\
\hline$m_{2}$ & Wheel mass & $33 \mathrm{~kg}$ \\
\hline $\boldsymbol{c}_{s}$ & Damping ratio & $1600 \mathrm{Ns} / \mathrm{m}$ \\
\hline $\boldsymbol{k}_{1}$ & Spring constant & $9000 \mathrm{~N} / \mathrm{m}$ \\
\hline $\boldsymbol{k}_{2}$ & Spring constant & $200000 \mathrm{~N} / \mathrm{m}$ \\
\hline
\end{tabular}

Tab. 1. Quarter car vehicle model parameters

Equations (1) can be represented in matrix form as:

$$
M \cdot \ddot{z}+C \cdot \dot{z}+K \cdot z=f_{a}
$$

where $M, C$, and $K$ represent the mass, damping, and stiffness matrices described by:

$$
\begin{gathered}
M=\text { diagonal }\left[m_{k}, m_{p}\right] \\
C=\left[\begin{array}{cc}
c_{s} & -c_{s} \\
-c_{s} & c_{s}
\end{array}\right] \\
K=\left[\begin{array}{cc}
k_{1} & -k_{1} \\
-k_{1} & k_{1}+k_{21}
\end{array}\right]
\end{gathered}
$$

Standard second order matrix form for the passive quarter car suspension system is shown in the following:

$$
\left[\begin{array}{cc}
m_{1} & 0 \\
0 & m_{2}
\end{array}\right] \cdot\left[\begin{array}{c}
\ddot{z}_{k} \\
\ddot{z}_{p}
\end{array}\right]+\left[\begin{array}{cc}
c_{s} & -c_{s} \\
-c_{s} & c_{s}
\end{array}\right] \cdot\left[\begin{array}{c}
\dot{z}_{k} \\
\dot{z}_{p}
\end{array}\right]+\left[\begin{array}{cc}
k_{1} & -k_{1} \\
-k_{1} & k_{1}+k_{2}
\end{array}\right] \cdot\left[\begin{array}{c}
z_{k} \\
z_{p}
\end{array}\right]-\left[\begin{array}{c}
0 \\
k_{2}
\end{array}\right] \cdot z_{r}=0
$$

For free vibration, the general form leads to:

$$
A \cdot z-B \cdot z=0
$$

The response of this system takes the form:

$$
z(t)=v \cdot e^{\lambda \cdot t}
$$

where $\boldsymbol{v}$ is a constant vector. 
The model represents a single wheel of a car in which the wheel is connected to the quarter portion of the car body through a hydropneumatic suspension.

Substituting (8) in (7) leads to eigenvalue problem;

$$
(A-\lambda \cdot B) \cdot v=0
$$

Vector $v$ is called the eigenvector and $\lambda$ represents eigenvalues.

\section{Natural frequencies and mode shapes simulation in Matlab}

Parametric studies of dynamical systems are an important task in all major engineering design. This is especially true in the design of control systems, when the focus is for low sensitivity to parameter variations (Likaj et al. 2005). It is important to know when one parameter is changed, how that affects the system; if the system becomes unstable, do the natural frequencies change, etc.

Since we have obtained matrices $M, C$, and $K$, we can calculate natural frequencies and mode shapes in MATLAB.

$m 1=200 ; m 2=33 ; c s=1600 ; k 1=9000 ; k 2=200000 ;$

$m=[m 10 ; 0 \mathrm{~m} 2]$;

$k=[k 1-k 1 ;-k 1 k 1+k 2]$;

$[u, l a m d a]=e i g(k, m)$;

$[u, \operatorname{lamda}]=\operatorname{eig}(k, m)$;

fprintf( $\left(\mathrm{n}^{\prime}\right)$

disp('Natural Frequencies are:')

$\%$ Print Natural Frequencies

$w=\operatorname{sqrt}($ lamda)

fprintf( $\left(\mathrm{n}^{\prime}\right)$

$\%$ Print the Mode Shape

disp('Mode shapes are:')

fprintf( $\left(\mathrm{n}^{\prime}\right)$

$\operatorname{disp}\left(\right.$ ' $\left.u={ }^{\prime}\right)$

fprintf( $\left(n^{\prime}\right)$

$\operatorname{disp}(u)$

Natural Frequencies are:

$w=$

$$
\begin{array}{cc}
6.5612 & 0 \\
0 & 79.5945
\end{array}
$$

Mode shapes are:

$u=$

$-0.0707-0.0012$

$-0.0031 \quad 0.1741$

Through simulation are obtained the values from V1 to V4 of a complex conjugate pairs of vectors using MATLAB with three different programming approaches. The simulation results are shown in Tab. 2 . 
Likaj, R.; Shala, A.; Bruqi, M. \& Bajrami, X.: Optimal Design and Analysis of Veh...

First approach:

$a=[m 1$ cs $k 1]$;

$b=[m 2$ cs $k 1+k 2]$;

$C=\operatorname{conv}(a, b)$

$d=[-c s-k 1]$

$e=\operatorname{conv}(d, d)$

$f=C-\left[\begin{array}{lll}0 & 0 & e\end{array}\right]$

$r=\operatorname{roots}(f)$

$C=1.0 e+09 *\left[\begin{array}{lllll}0.0000 & 0.0004 & 0.0447 & 0.3488 & 1.8810\end{array}\right]$

$e=\left[\begin{array}{lll}2560000 & 28800000 & 81000000\end{array}\right]$

$f=1.0 e+09 *\left[\begin{array}{lllll}0.0000 & 0.0004 & 0.0421 & 0.3200 & 1.8000\end{array}\right]$

$\%$ poles of the system

$r=$

$-24.3582+73.2172 i$

$-24.3582-73.2172 i$

$-3.8842+5.5424 i$

$-3.8842-5.5424 i$

Second approach,

$t=[0: 0.01: 3]^{\prime} ;$

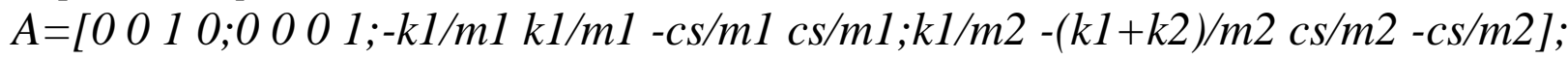

$B=[0 ; 0 ; 1 / \mathrm{ml} ;-1 / \mathrm{m} 2]$;

$C=\left[\begin{array}{lllllll}1 & 0 & 0 & 0 ; 0 & 1 & 0 & 0\end{array}\right]$

$D=[0 ; 0]$;

[num, den] $=\operatorname{ss} 2 t f(A, B, C, D)$;

$\operatorname{sys}=\operatorname{ss}([A],[B],[C],[D])$;

$[r, p, k]=$ residue(num,den)

$r=$

$-7.1146-15.0873 i$

$-7.1146+15.0873 i$

$0.0009+0.0011 i$

$0.0009-0.0011 i$

$p=$

$-24.3582+73.2172 i$

$-24.3582-73.2172 i$

$-3.8842+5.5424 i$

$-3.8842-5.5424 i$

$k=$

$0.0050-0.3127$

Third approach: Frequency response and poles of the system

$M=[m 10 ; 0 \mathrm{~m} 2]$;

$K=[k 1-k 1 ;-k 1 k 1+k 2]$;

$C=[c s-c s ;-c s c s]$;

$\%$ determination of frequency response and phase

$A=[z \operatorname{eros}(2,2)$ eye $(2) ;-K$ zeros $(2,2)]$;

$B=[\operatorname{eye}(2) z \operatorname{eros}(2,2) ; C M]$; 
$[v, s]=\operatorname{eig}(A, B)$

figure(1)

$\operatorname{plot}\left(s,{ }^{\prime}.\right)$

$v 1=v(:, 1)$;

$v 2=v(:, 3)$;

$v 3=v(:, 2)$;

$v 4=v(:, 4)$;

grid on;

$v=-0.0011+0.0008 i-0.0011-0.0008 i-0.0991-0.0395 i-0.0991+0.0395 i$

$-0.0042-0.0120 i-0.0042+0.0120 i \quad 0.0002-0.0049 i \quad 0.0002+0.0049 i$

$-0.0317-0.0984 i-0.0317+0.0984 i \quad 0.6039-0.3961 i \quad 0.6039+0.3961 i$

$0.9834-0.0166 i \quad 0.9834+0.0166 i \quad 0.0264+0.0200 i \quad 0.0264-0.0200 i$ $s=$

$\begin{array}{llll}-24.3582+73.2172 i & 0 & 0 & 0\end{array}$

0
0 $\quad \begin{array}{cccc}-24.3582-73.2172 i & 0 & 0 \\ 0 & 0 & -3.8842+5.5424 i\end{array}$

$\begin{array}{llll}0 & 0 & 0 & -3.8842-5.5424 i\end{array}$

Equation (9) is the governing equation and computer simulations will be used for further results.

As we can see for all cases have been obtained similar results. The results are shown in Tab. 2 and Fig. 2/ Fig.3/Fig.4.

\begin{tabular}{|r|r|}
\hline Poles & Value \\
\hline s11 & $-24.3582+73.2172 \mathrm{i}$ \\
\hline $\mathrm{s} 22$ & $-24.3582-73.2172 \mathrm{i}$ \\
\hline $\mathrm{s} 33$ & $-3.8842+5.5424 \mathrm{i}$ \\
\hline $\mathrm{s} 44$ & $-3.8842-5.5424 \mathrm{i}$ \\
\hline
\end{tabular}

Tab. 2. Poles of the system
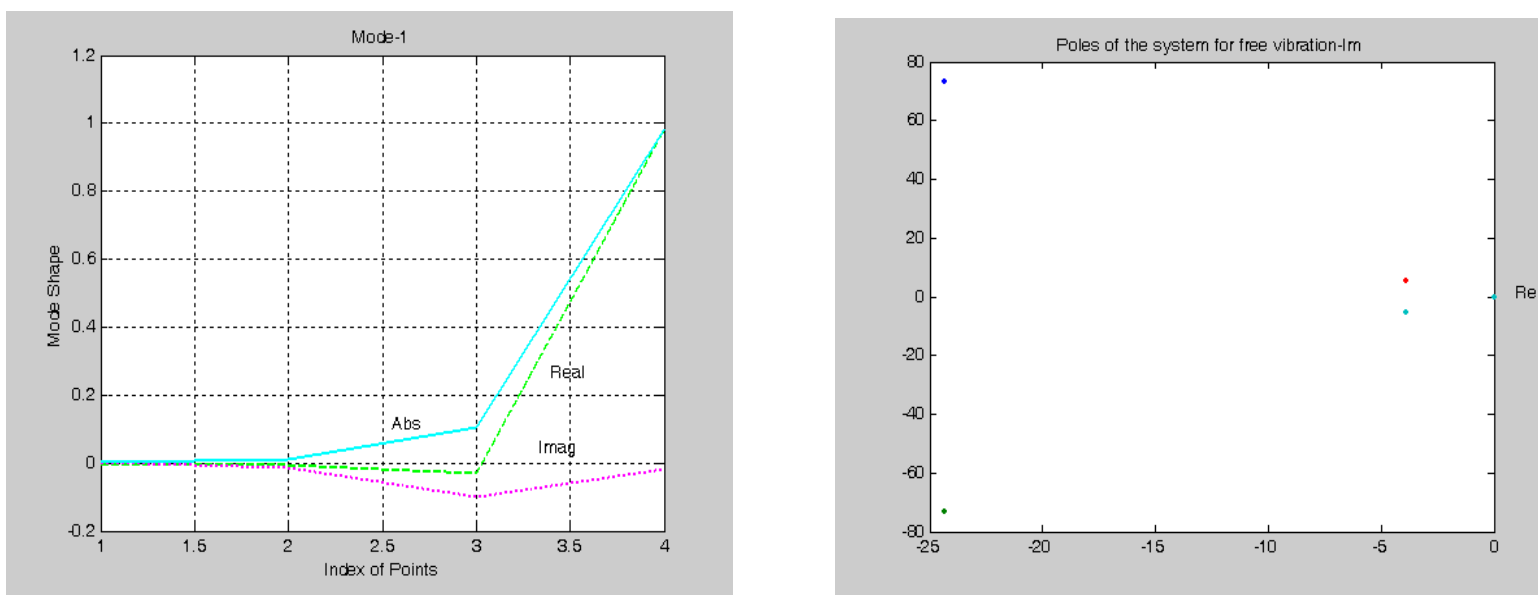

Fig. 2. Poles of the system

Fig. 3. First mode shape 
Likaj, R.; Shala, A.; Bruqi, M. \& Bajrami, X.: Optimal Design and Analysis of Veh...

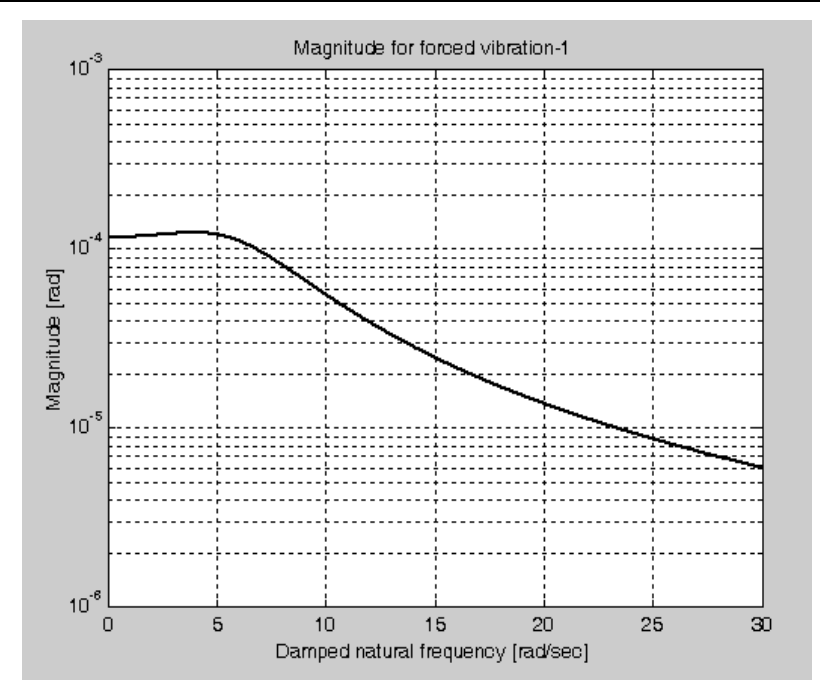

Fig. 4. Magnitude for forced vibrations

The result above indicates that the first and second damped natural frequencies are:

$$
\begin{gathered}
\omega_{d 1}=\omega_{n 1} \sqrt{1-\varsigma_{1}^{2}}=6.5612 \sqrt{1-0.592^{2}} \approx 5.28792[\mathrm{rad} / \mathrm{s}] \\
\omega_{d 2}=\omega_{n 2} \sqrt{1-\varsigma_{2}^{2}}=79.5945 \sqrt{1-0.306^{2}}[\mathrm{rad} / \mathrm{s}]
\end{gathered}
$$

The negative sign in front of the real part of the complex roots indicates the decaying nature of the oscillation:

$$
\begin{aligned}
-\varsigma_{1} \omega_{n 1} & =-3.8842 \quad[\mathrm{rad} / \mathrm{s}] \\
-\varsigma_{2} \omega_{n 2} & =-24.3582[\mathrm{rad} / \mathrm{s}]
\end{aligned}
$$

From the equations (10) and (11), the natural frequencies are:

$$
\begin{gathered}
\omega_{n 1}=\frac{-3.8842}{-0.592} \approx 6.5612\left[\begin{array}{rl}
{[\mathrm{rad} / \mathrm{s}]} & \text { and } \omega_{n 2}=\frac{-24.3582}{-0.306} \approx 79.602[\mathrm{rad} / \mathrm{s}] \\
\varsigma_{1} & \approx 0.592 \\
\varsigma_{2} & \approx 0.306
\end{array}\right.
\end{gathered}
$$

While natural frequencies are:

$$
\begin{aligned}
& f_{1}=\frac{\omega_{n 1}}{2 \pi}=\frac{6.5612}{2 \pi} \approx 1.04425 \mathrm{~Hz} \\
& f_{2}=\frac{\omega_{n 2}}{2 \pi}=\frac{79.5945}{2 \pi} \approx 12.66786 \mathrm{~Hz}
\end{aligned}
$$


First and second natural frequencies calculated by general principles of theory of vibrations are given in the following:

$$
\begin{aligned}
& \omega_{n 1}=\sqrt{\frac{k_{1}}{m_{1}}}=\sqrt{\frac{9000}{200}}=6.708[\mathrm{rad} / \mathrm{sec}] \\
& \omega_{n 2}=\sqrt{\frac{k_{2}}{m_{2}}}=\sqrt{\frac{200000}{33}}=77.845[\mathrm{rad} / \mathrm{sec}] \\
& \zeta_{1}=\frac{c_{s}}{2 \cdot \sqrt{k_{1} \cdot m_{1}}}=\frac{1600}{2 \cdot \sqrt{9000 \cdot 200}} \approx 0.5963 \\
& \zeta_{2}=\frac{c_{s}}{2 \cdot \sqrt{k_{2} \cdot m_{2}}}=\frac{1600}{2 \cdot \sqrt{200000 \cdot 33}} \approx 0.3113996 \\
& f_{1}=\frac{\omega_{n 1}}{2 \pi}=\frac{6.708}{2 \pi} \approx 1.0676 \mathrm{~Hz} \\
& f_{2}=\frac{\omega_{n 2}}{2 \pi}=\frac{77.845}{2 \pi} \approx 12.389 \mathrm{~Hz}
\end{aligned}
$$

From the results of the natural frequencies obtained in both ways it can be concluded that the values are almost the same.

\section{Stability of the model by Lyapunov theorem in Matlab}

The Lapunov criterion will be used to check whether or not the given system is stable. Starting point for stability analysis is state-space form of system (Jadlovska, A. et al., 2013, Likaj, R. 2003). Matrix $\boldsymbol{A}$ must be definite, x is the state vector containing $n$ state variables. The quadratic form of Lyapunov function is:

$$
V(x)=x^{T}(t) \cdot Q \cdot x(t)
$$

where $Q$ must be a positive definite symmetric matrix $n \times n$. General form of Lyapunov matrix equation is:

$$
A \cdot Q+Q \cdot A^{T}=-C
$$
$Q=I$.

Where $\boldsymbol{C}$ is a positive definite symmetric matrix. Usually, matrix $\boldsymbol{Q}$ is taken

From MATLAB, for closed loop is:

$>>m 1=200 ; m 2=33 ; c s=1600 ; k 1=9000 ; k 2=200000$;

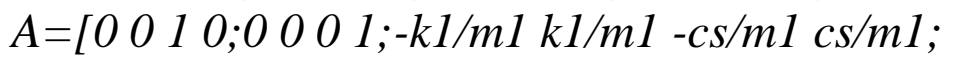

$k 1 / m 2-(k 1+k 2) / m 2 \mathrm{cs} / \mathrm{m} 2-c s / m 2]$;

$B=[0 ; 0 ; 1 / \mathrm{ml} ;-1 / \mathrm{m} 2]$;

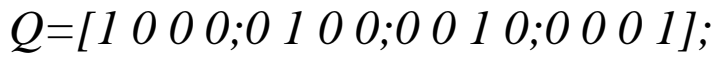

$X=l y a p(A, Q)$;

$A * Q+Q *$ transpose $(A)$

$K=\left[\begin{array}{llll}0.01 & 1 & 0.01 & 0.1\end{array}\right]$; 
Likaj, R.; Shala, A.; Bruqi, M. \& Bajrami, X.: Optimal Design and Analysis of Veh...

$$
\begin{aligned}
& \text { eig }(A-B * K) \\
& \quad \text { ans }= \\
& -24.3567+73.2176 i \\
& -24.3567-73.2176 i \\
& -3.8842+5.5424 i \\
& -3.8842-5.5424 i
\end{aligned}
$$$$
\begin{aligned}
& C= \\
& \left.\begin{array}{clrr}
C=0 e+03 * & & & \\
0 & 0 & -0.0440 & 0.2727 \\
0 & 0 & 0.0450 & -6.3323 \\
-0.0440 & 0.0450 & -0.0160 & 0.0565 \\
0.2727 & -6.3323 & 0.0565 & -0.0970 \\
\text { ans }= & & &
\end{array}\right]
\end{aligned}
$$

$7.0942 e+10$

Since all real roots of conjugate pairs are negative, and $C$ is positive the model of the system is asymptotically stable.

\section{Transfer function}

The transfer function of a linear time invariant system or a section of the system represents the ratio of the Laplace transform of the output to the Laplace transform of the input. The Laplace transforms are obtained directly from the differential equations describing the system. The transfer function thus contains basic information concerning the essential characteristics of a system without any regard to initial conditions or excitation.

For the simplicity in the making equations, let's assume:

$$
\begin{aligned}
& z_{k}=x_{1}, \quad \frac{d z_{k}}{d t}=\dot{x_{1}}=x_{3}, \\
& z_{p}=x_{2}, \quad \frac{d z_{p}}{d t}=\dot{x_{2}}=x_{4}, \\
& \dot{x_{3}}=\frac{f_{a}}{m_{k}}-\frac{k_{1}}{m_{k}} z_{k}+\frac{k_{1}}{m_{k}} z_{p}-\frac{c_{s}}{m_{k}} \dot{z}_{k}+\frac{c_{s}}{m_{k}} z_{p} \\
& \text { respectively: } \\
& \dot{x_{3}}=\frac{f_{a}}{m_{k}}-\frac{k_{1}}{m_{k}} x_{1}+\frac{k_{1}}{m_{k}} x_{2}-\frac{c_{s}}{m_{k}} x_{3}+\frac{c_{s}}{m_{k}} x_{4} \\
& \dot{x_{4}}=-\frac{f_{a}}{m_{p}}+\frac{k_{1}}{m_{p}} z_{k}-\frac{k_{1}}{m_{p}} z_{p}+\frac{c_{s}}{m_{p}} z_{k}-\frac{c_{s}}{m_{p}} \dot{z}_{p}-\frac{k_{2}}{m_{p}} z_{p}+\frac{k_{2}}{m_{p}} z_{r}
\end{aligned}
$$

respectively:

$$
\dot{x_{4}}=-\frac{f_{a}}{m_{p}}+\frac{k_{1}}{m_{p}} x_{1}-\frac{\left(k_{2}+k_{1}\right)}{m_{p}} x_{2}+\frac{c_{s}}{m_{p}} x_{3}-\frac{c_{s}}{m_{p}} x_{4}+\frac{k_{2}}{m_{p}} z_{r}
$$

Transfer function written in Matlab:

$m 1=200 ; m 2=33 ; c s=1600 ; k 1=9000 ; k 2=200000 ; t=[0: 0.01: 3]^{\prime} ;$ 


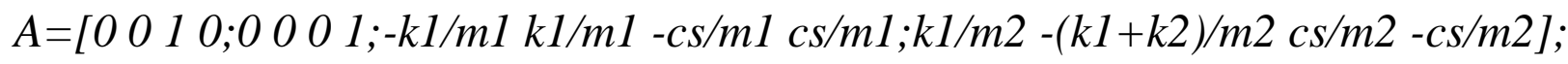

$B=[0 ; 0 ; 1 / \mathrm{ml} ;-1 / \mathrm{m} 2]$;

$C=\left[\begin{array}{lllllll}1 & 0 & 0 & 0 ; 0 & 1 & 0 & 0\end{array}\right]$;

$D=[0 ; 0]$;

[num, den] $=\operatorname{ss} 2 t f(A, B, C, D)$;

sys $=\operatorname{ss}([A],[B],[C],[D])$;

tf(sys)

ans $=$

From input to output...

$1:$

$0.005 s^{\wedge} 2+7.821 e-16 s+30.3$

$s^{\wedge} 4+56.48 s^{\wedge} 3+6378 s^{\wedge} 2+4.848 e 04 s+2.727 e 05$

2:

$$
-0.0303 s^{\wedge} 2-3.553 e-17 s+1.699 e-16
$$

$s^{\wedge} 4+56.48 s^{\wedge} 3+6378 s^{\wedge} 2+4.848 e 04 s+2.727 e 05$

\section{Laplace transform}

The Laplace transform technique provides a useful and simple method to evaluate the performance of a control system.

This integral transform is used to simplify the solution of linear differential equations by converting the differential equation into an algebraic equation.

Now, taking Laplace transform for homogenous part of equations of motion given above, we will have.

$$
\begin{aligned}
& m_{1} s^{2} x_{1}(s)-k_{1} x_{2}(s)+k_{1} x_{1}(s)-c_{s} s x_{2}(s)+c_{s} s x_{1}(s)=0 \\
& m_{2} s^{2} x_{2}(s)+k_{2} x_{2}(s)-k_{2} x_{r}(s)+k_{1} x_{2}(s)-k_{1} x_{1}(s)+c_{s} s x_{2}(s)-c_{s} s x_{1}(s)=0
\end{aligned}
$$

In matrix form:

$$
\left[\begin{array}{cc}
-\left(k_{1}+c_{s} s\right) & \left(m_{k} s^{2}+k_{1}+c_{s} s\right) \\
\left(m_{p} s^{2}+k_{2}+k_{1}+c_{s} s\right) & -\left(k_{1}+c_{s} s\right)
\end{array}\right] \cdot\left[\begin{array}{c}
x_{1}(s) \\
x_{2}(s)
\end{array}\right]+\left[\begin{array}{c}
0 \\
-k_{2}
\end{array}\right] \cdot x_{r}=0
$$

Finally the transfer function of quarter car suspension system is:

$$
F(s)=\frac{x_{1}(s)}{x_{2}(s)}=\frac{k_{2}\left(k_{1}+c_{s} s\right)}{m_{2} m_{1} s^{4}+\left(m_{1}+m_{2}\right) c_{s} s^{3}+\left[k_{2} m_{1}+\left(m_{1}+m_{2}\right) k_{1}\right] s^{2}+k_{2} c_{s} s+k_{2} k_{1}}
$$

Transfer function in Matlab

$m 1=200 ; m 2=33 ; c s=1600 ; k 1=9000 ; k 2=200000$;

syms $t s$

$F=t f([k 2 * k 1 * c s \quad k 2 * k 1],[m 2 * m 1(m 1+m 2) * c s k 2 * m 1+(m 2+m 1) * k 1 k 2 * c s k 2 * k 1])$; 
Likaj, R.; Shala, A.; Bruqi, M. \& Bajrami, X.: Optimal Design and Analysis of Veh...

$$
\begin{aligned}
& >>F \\
& F=
\end{aligned}
$$$$
2.88 e 12 s+1.8 e 09
$$$$
6600 s^{\wedge} 4+372800 s^{\wedge} 3+4.21 e 07 s^{\wedge} 2+3.2 e 08 s+1.8 e 09
$$

Continuous-time transfer function.

num $=$ [2.88e12 1.8e09];

den=[6600 $3728004.21 e 073.2 e 08$ 1.8e09];

$G=t f($ num,den $)$

$[A, B, C, D]=\operatorname{ssdata}(G)$

$G=$

$$
2.88 e 12 s+1.8 e 09
$$

$6600 s^{\wedge} 4+372800 s^{\wedge} 3+4.21 e 07 s^{\wedge} 2+3.2 e 08 s+1.8 e 09$

Continuous-time transfer function.

$A=-$

$\begin{array}{llll}56.4848 & -99.6686 & -23.6742 & -8.3230\end{array}$

$\begin{array}{cccc}64.0000 & 0 & 0 & 0 \\ 0 & 32.0000 & 0 & 0 \\ 0 & 0 & 16.0000 & 0\end{array}$

$B=$

512

0

0

0

$C=0 \quad 0 \quad 416.1488 \quad 0.0163$

$D=0$

or

$>>m 1=200 ; m 2=33 ; c s=1600 ; k 1=9000 ; k 2=200000 ;$

syms $t s$

$F=\left[k 2 *\left(k 1+c s^{*} s\right)\right] /\left[\left(m 2 * m 1 * s^{\wedge} 4+(m 1+m 2) * c s^{*} s^{\wedge} 3+(k 2 * m 1+(m 2+m 1) * k 1)\right) * s^{\wedge} 2+k\right.$ $\left.2 * c *^{*} s+k 2 * k 1\right]$

laplace $(F)$

ans $=$

$1800000000 *$ laplace $\left(1 /\left(6600 * *^{\wedge} 6+372800 * s^{\wedge} 5+42097000 * s^{\wedge} 2+320000000 * s+\right.\right.$ $1800000000), \quad s, \quad z)+320000000 *$ laplace $\left(s /\left(6600 * s^{\wedge} 6+372800 * s^{\wedge} 5+\right.\right.$ $\left.\left.42097000 * *^{\wedge} 2+320000000 * s+1800000000\right), s, z\right)$

\section{Full controllability}

If any modes of the open-loop system are unstable, they can be stabilized with a feedback using linear quadratic control. A necessary condition for solving the controller problem is that the system is controllable. This means that all the modes 
can be excited or controlled by the input $u$. In terms of the state space matrices, the condition of controllability can be shown by constructing the controllability matrix $Q c$ defined by:

$$
Q_{c}=\left[B, A B, \ldots, A^{m-1} B\right]
$$

Controllability is ensured when the rank of $\mathrm{Q}_{\mathrm{C}}$ equals $m$, where $m$ is the order of the system.

\section{State controllability}

A system is said to be "(state) controllable" if for any $t_{0}$ and any initial state $x\left(t_{0}\right)=x_{0}$ and any final state $x_{f}$, there exists a finite time $t_{1}>t_{0}$ and control $u(t)$, such that $x\left(t_{1}\right)=x_{f}$.

A LTI system with the state equation $\dot{x}=A x+B u$ is controllable if the controllability matrix $Q c=\left[B, A B, A^{2} B, \ldots, A^{m-1} B\right]$ has rank $m$.

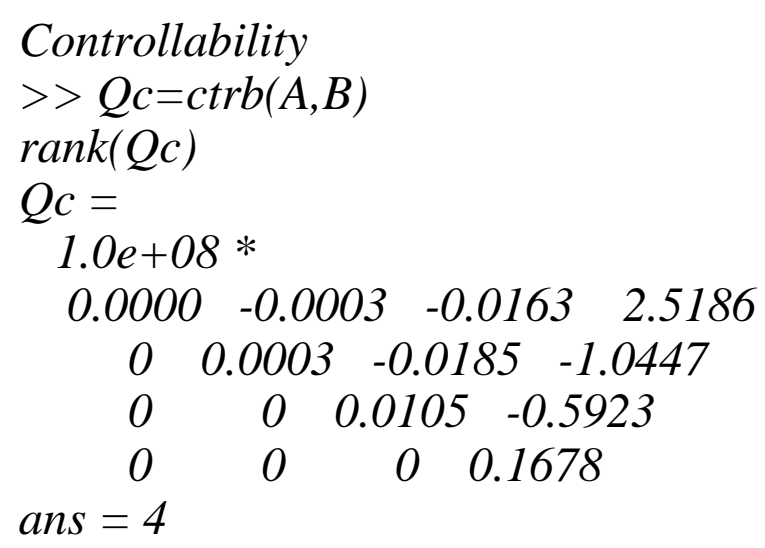

Since rank of $Q c$ is 4 equals with size of matrix A, system is controllable.

\section{State observability}

A system is said to be "(state) observable" if for any $t_{0}$ and any initial state $x\left(t_{0}\right)=x_{0}$ there exists a finite time $t_{1}>t_{0}$ such that knowledge of $u(t)$ and $y(t)$ for $t_{0} \leq t \leq t_{1}$ suffices to determine $x_{0}$

A LTI system with the state space model

$$
\begin{gathered}
\dot{x}=A x+B u \\
y=C x
\end{gathered}
$$

is observable only if observability matrix $Q_{0}=\left[C, C A, C A^{2}, \ldots, C \mathrm{~A}^{n-1}\right]^{\mathrm{T}}$ has rank $n$. Functions in MATLAB 
Likaj, R.; Shala, A.; Bruqi, M. \& Bajrami, X.: Optimal Design and Analysis of Veh...

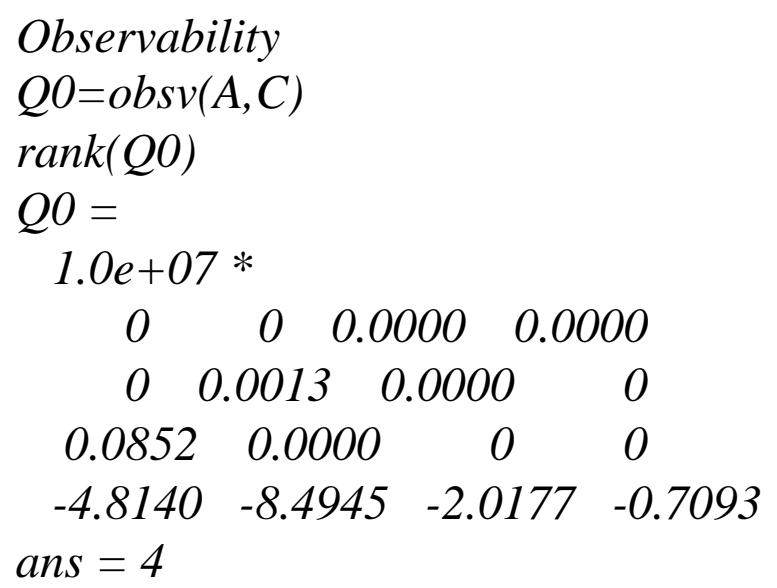

Since rank of $Q o$ is 4 equals with size of matrix A, system is observable.

\section{Stochastic road modeling and PSD response}

Road irregularity or unevenness represents the main disturbing source for either the rider or vehicle structure itself. The road profile elevation is usually expressed in terms of the power spectral density (PSD). The PSD of the road profile elevation is expressed as:

$$
G_{q}(n)=G_{q}\left(n_{0}\right)\left(n / n_{0}\right)^{-w}
$$

For the purposes of design optimization, according to James' principle, the root mean square (RMS) of the sprung mass acceleration $\ddot{z}_{2}$ can be expressed as:

$$
\sigma_{z}=\left\{\pi R V\left[\frac{k_{2} c_{s}}{2 m_{1}^{3 / 2} k_{1}^{1 / 2}}+\frac{\left(m_{1}+m_{2}\right) \mathrm{k}_{1}^{2}}{2 c_{s} m_{1}^{2}}\right]\right\}^{1 / 2}
$$

The RMS of the suspension working space $f_{d}$ is:

$$
\sigma_{f d}=\left\{\pi R V\left[\frac{\left(m_{1}+m_{2}\right)\left(m_{1} \mathrm{k}_{1}\right)^{1 / 2}}{2 m_{1} c_{s}}\right]\right\}^{1 / 2}
$$

The RMS of the relative dynamic tire load can be calculated as:

$$
\sigma_{F d / G}=\left\{\pi R V\left[\frac{k_{2}^{2} m_{2}}{2 c_{s}\left(m_{1}+m_{2}\right)^{2}}+\frac{\left(m_{1}+m_{2}\right) \mathrm{k}_{1}^{2}}{2 m_{1}^{2} c_{s}}-\frac{k_{2} k_{1} m_{2}}{c_{s} m_{1}\left(m_{1}+m_{2}\right)}+\frac{c_{s} k_{1}}{2 m_{1} m_{2}}\right]\right\}^{1 / 2}
$$




\section{Design optimisation}

In this section, the sprung mass vertical acceleration is minimized, while the design constraints on the suspension working space and dynamic tire load should be satisfied. To implement the design optimization, the two optimization algorithms, i.e, SQP and GA, will be applied, respectively.

\section{Optimization based on SQP algorithm and GA}

The SQP algorithm is a non-linear programming technique that is used for the purpose of minimizing a smooth non-linear function subjected to a set of constraints with upper and lower bounds. The objective function and the constraint functions are assumed to be at least twice continuously differentiable. This algorithm is a gradientbased search method (Likaj, R. et al., 2009, Zhongzhe, Ch., et al., 2008). This algorithm is well-suited for constrained design optimizations.

The reliability for finding the optimum decreases with the increase of number of design variables when using SQP method. In contrast, whether the number of design variables increase the GA can still reliably find the optimum. This can be explained by the fact that GA works on a population of variables in parallel, not on a unique point. GAs are global search methods that are based on the Darwin's principle of natural selection and genetic modification. The GA has higher reliability to find the global optimum with minimum number of computational operations.

The RMS of the acceleration of a sprung mass ${ }^{\bar{z}_{z_{k}}}$ is frequently used to evaluate the riding quality of a vehicle. A rider's comfort improves as the acceleration decreases. Ride comfort is chosen to be the design criterion. The suspension working space and dynamic tire load ${ }^{\sigma_{f d}}$ are selected as the design constraints. The design variables are $m_{1}, m_{2}, K_{t}, K$ and $C$, respectively.

Thus, the design optimization problem can be described as:

Minimise:

$$
\begin{aligned}
\sigma_{z_{k}}\left(m_{1}, m_{2}, \mathrm{k}_{2}, \mathrm{k}_{1}, \mathrm{c}_{s}\right) & =\left\{\pi R V\left[\frac{k_{2} c_{s}}{2 m_{1}^{3 / 2} k_{1}^{1 / 2}}+\frac{\left(m_{1}+m_{2}\right) \mathrm{k}_{1}^{2}}{2 c_{s} m_{1}^{2}}\right]\right\}^{1 / 2} \\
\text { Subject to: } & \left\{\begin{array}{l}
\sigma_{F d / G}\left(m_{1}, m_{2}, \mathrm{k}_{1}, \mathrm{k}_{2}, \mathrm{c}_{s}\right) \leq a=0.5 \\
\sigma_{f d}=\left(m_{1}, m_{2}, \mathrm{k}_{1}, \mathrm{k}_{2}, \mathrm{c}_{s}\right) \leq b=0.05 \\
150 \leq m_{1} \leq 200 \\
32 \leq m_{2} \leq 40 \\
200000 \leq k_{2} \leq 220000 \\
8500 \leq k_{1} \leq 91000 \\
1580 \leq c_{s} \leq 1861
\end{array}\right.
\end{aligned}
$$


Likaj, R.; Shala, A.; Bruqi, M. \& Bajrami, X.: Optimal Design and Analysis of Veh...

In this sub-section, the optimization results are derived for a vehicle travelling at the speed of $40 \mathrm{~m} / \mathrm{s}$ on the road with an irregularity coefficient of power spectrum taking the value of $6.5 \times 10^{-6} \mathrm{~m}^{3}$.

\begin{tabular}{|r|r|r|r|}
\hline & Original values & SQP method & GA \\
\hline $\begin{array}{r}\text { Initial } \\
\text { values }\end{array}$ & & {$[1010101010]$} & {$[1010101010]$} \\
\hline $\mathrm{m}_{1}[\mathrm{~kg}]$ & 200 & 200.0 & 199.918612498565 \\
\hline $\mathrm{m}_{2}[\mathrm{~kg}]$ & 33 & 32.0 & 32.04226032330942 \\
\hline $\mathrm{k}_{2}[\mathrm{~N} / \mathrm{m}]$ & 200000 & 200000.0 & 200305.81925474654 \\
\hline $\mathrm{k}_{1}[\mathrm{~N} / \mathrm{m}]$ & 9000 & 9100.0 & 9099.82776078753 \\
\hline $\mathrm{cs}[\mathrm{Ns} / \mathrm{m}]$ & 1600 & 1580.0 & 1591.7473971815848 \\
\hline$\sigma_{z_{1}}^{\cdot}$ & & 1.2673254442031 & 1.26976709377 \\
\hline & & $\begin{array}{r}\text { Optimum found: } 52 \\
\text { iterations }\end{array}$ & $\begin{array}{r}\text { Optimum found: } 51 \\
\text { generations }\end{array}$ \\
\hline
\end{tabular}

Tab. 3. Optimal design variables based on the SQP and GA for minimizing the sprung mass vertical acceleration, vehicle speed $40 \mathrm{~m} / \mathrm{s}$

\section{Fuzzy logic controller}

Fuzzy Logic Control has accelerated in recent years in many areas, including feedback control. By using empirical rules according to the designers knowledge and experience, which are represented linguistically with the conditional statements and resulting assertion.

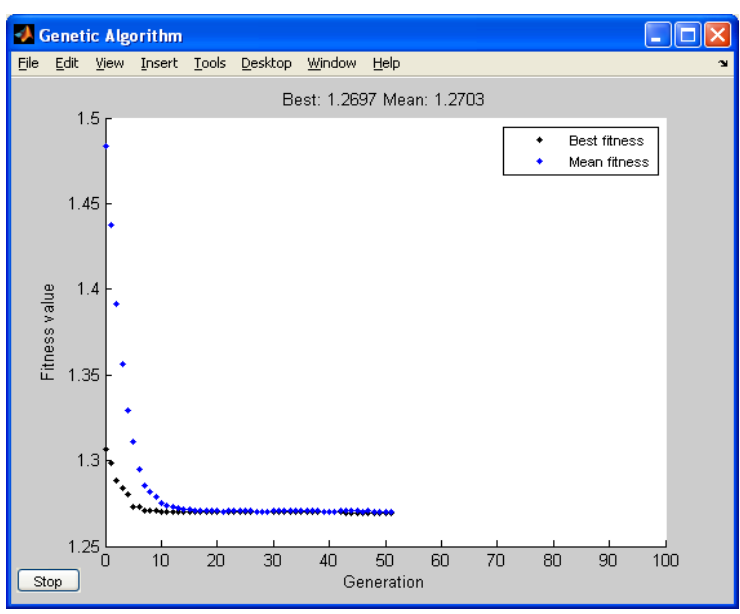

Fig. 5. Fitness value GA

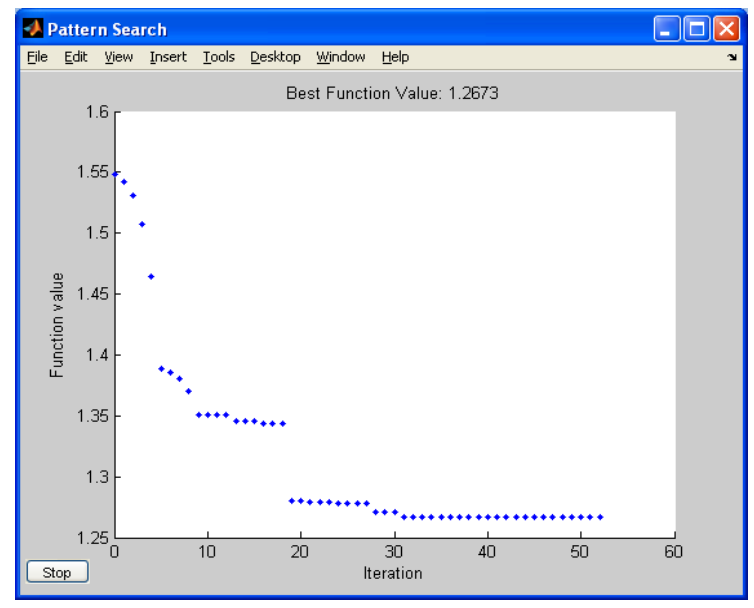

Fig. 6. Fitness value SQP 
A fuzzy rule base has a very significant effect on the control strategy in FLC, in other words it defines the strategy of the controller. To the active suspension system there are at least three main objectives, namely ride comfort, suspension travel and handling. The rule base can be tuned to improve each of the above objectives.

The fuzzy logic controller used in the active suspension has three inputs: body acceleration $\ddot{z}_{b}$, body velocity $\dot{z}_{b}$, body deflection velocity $\dot{z}_{b}-\dot{z}_{t}$ and one output: desired actuator force $f_{a}$, shown in Fig. 8 .

$$
f_{a}=\frac{\int_{f_{a}} f^{*} \mu_{D}(f) d f}{\int_{f_{a}} \mu_{D}(f) d f}
$$

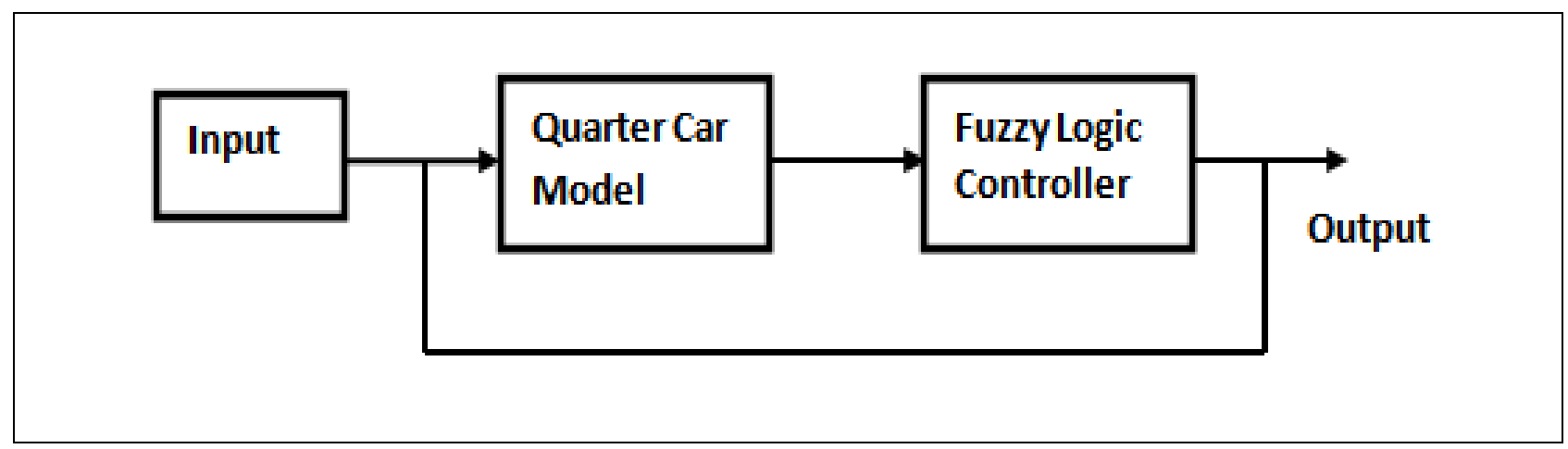

Fig. 7. Control scheme of quarter car model

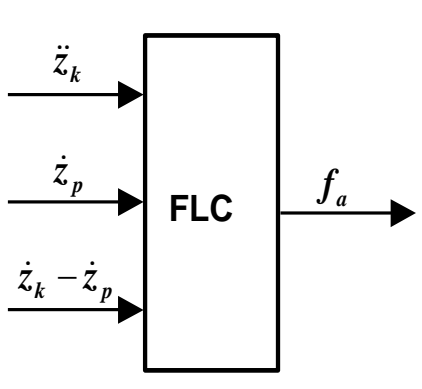

Fig. 8. Inputs and output of FLC

The control system itself consists of three steps: fuzzification, fuzzy inference machine and deffuzification. During the fuzzification process the real numbers (crisp) inputs will be converted into fuzzy values, where after fuzzy interference machine processes the input data and computes in cope with the rule base and database. The obtained outputs (fuzzy values) are converted into real numbers by the defuzzification step. Membership functions are chosen for the inputs and the output variables with the following variables: NV-negative very big, NB-negative big, NMnegative medium, NS-negative small, N-negative, ZE-zero, P-positive, PS-positive small, PM-positive medium, PB-positive big, PV-positive very big.

The fuzzy rule based system modelled by designer's knowledge and experience is shown in Fig. 9. (Likaj, R. et al., 2002, Cai \& Konik, 1993, Likaj, R., 2003). Rule Editor in Matlab is shown in Fig. 10. 
Likaj, R.; Shala, A.; Bruqi, M. \& Bajrami, X.: Optimal Design and Analysis of Veh...

Rules of the controller have the following general form:

$R_{i}:$ IF $<z_{b} i s A_{i} A N D<z_{b} i s B_{i}>A N D<z_{b}-z_{t} i s C_{i}$,

THEN $<f_{a} i s D_{i}>$.

Where: $A_{i}, B_{i}, C_{i}$ and $D_{i}$ are labels of fuzzy sets representing the linguistic values of $\dot{z}_{b}-\dot{z}_{t}, \dot{z}_{b}, \ddot{z}_{b}$ and $f_{a}$, which are characterised by their membership functions: $-1 \leq z_{b}-z_{t} \leq 1 ;-1 \leq \dot{z}_{b} \leq 1 ;-4 \leq \ddot{z}_{b} \leq 4 ;-4000 \leq f_{a} \leq 4000$.

Results of simulation for the passive quarter car model are shown in Fig.13 /Fig.14. The results of simulation for active quarter car model are shown in Fig.15/Fig.16, while the acceleration of unsprunged mass for passive quarter car model is shown in Fig. 17. Accelerations of the active quarter car model are shown in Fig. 18/Fig.19.

\begin{tabular}{|l|l|l|l|}
\hline$\ddot{z}_{b}$ & $\dot{z}_{b}$ & $\dot{z}_{b}-\dot{z}_{t}$ & $f_{a}$ \\
\hline$Z \mathrm{E}$ & $\mathrm{P}$ & $\mathrm{P}$ & $\mathrm{NS}$ \\
\hline$Z \mathrm{E}$ & $\mathrm{P}$ & $\mathrm{ZE}$ & $\mathrm{NM}$ \\
\hline$Z \mathrm{E}$ & $\mathrm{P}$ & $\mathrm{N}$ & $\mathrm{NB}$ \\
\hline$Z \mathrm{E}$ & $\mathrm{ZE}$ & $\mathrm{P}$ & $\mathrm{PS}$ \\
\hline $\mathrm{ZE}$ & $\mathrm{ZE}$ & $\mathrm{ZE}$ & $\mathrm{ZE}$ \\
\hline $\mathrm{ZE}$ & $\mathrm{ZE}$ & $\mathrm{N}$ & $\mathrm{NS}$ \\
\hline $\mathrm{ZE}$ & $\mathrm{N}$ & $\mathrm{P}$ & $\mathrm{PB}$ \\
\hline $\mathrm{ZE}$ & $\mathrm{N}$ & $\mathrm{ZE}$ & $\mathrm{PM}$ \\
\hline$Z \mathrm{E}$ & $\mathrm{N}$ & $\mathrm{N}$ & $\mathrm{PS}$ \\
\hline $\mathrm{P}$ or $\mathrm{N}$ & $\mathrm{P}$ & $\mathrm{P}$ & $\mathrm{NM}$ \\
\hline $\mathrm{P}$ or $\mathrm{N}$ & $\mathrm{P}$ & $\mathrm{ZE}$ & $\mathrm{NB}$ \\
\hline $\mathrm{P}$ or $\mathrm{N}$ & $\mathrm{P}$ & $\mathrm{N}$ & $\mathrm{NV}$ \\
\hline $\mathrm{P}$ or $\mathrm{N}$ & $\mathrm{ZE}$ & $\mathrm{P}$ & $\mathrm{PM}$ \\
\hline $\mathrm{P}$ or $\mathrm{N}$ & $\mathrm{ZE}$ & $\mathrm{ZE}$ & $\mathrm{ZE}$ \\
\hline $\mathrm{P}$ or $\mathrm{N}$ & $\mathrm{ZE}$ & $\mathrm{N}$ & $\mathrm{NM}$ \\
\hline $\mathrm{P}$ or $\mathrm{N}$ & $\mathrm{N}$ & $\mathrm{P}$ & $\mathrm{PV}$ \\
\hline $\mathrm{P}$ or $\mathrm{N}$ & $\mathrm{N}$ & $\mathrm{ZE}$ & $\mathrm{PB}$ \\
\hline
\end{tabular}

Fig. 9. Fuzzy rules

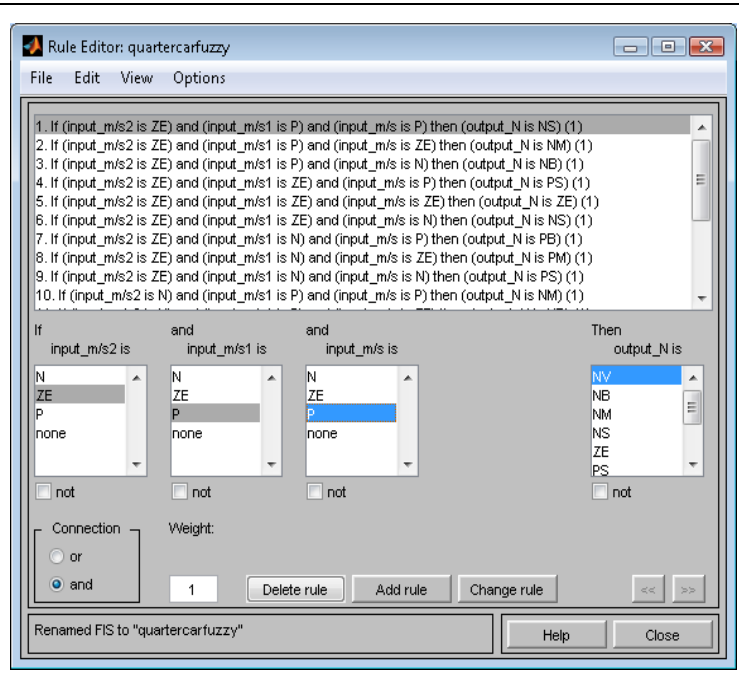

Fig. 10. Rule Editor in Matlab 
The output of the fuzzy controller $\mu_{D}$ is corresponding membership function.

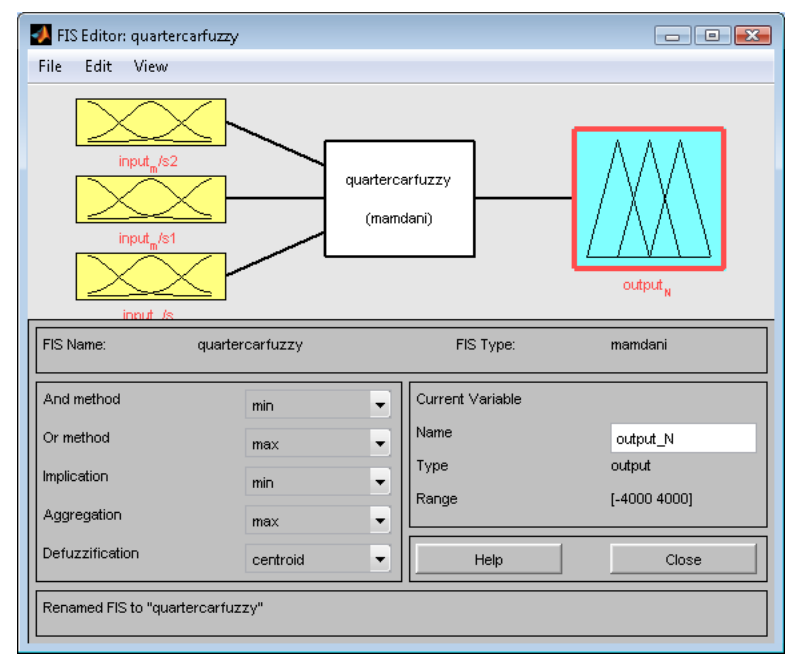

Fig. 11. FIS Editor in Matlab

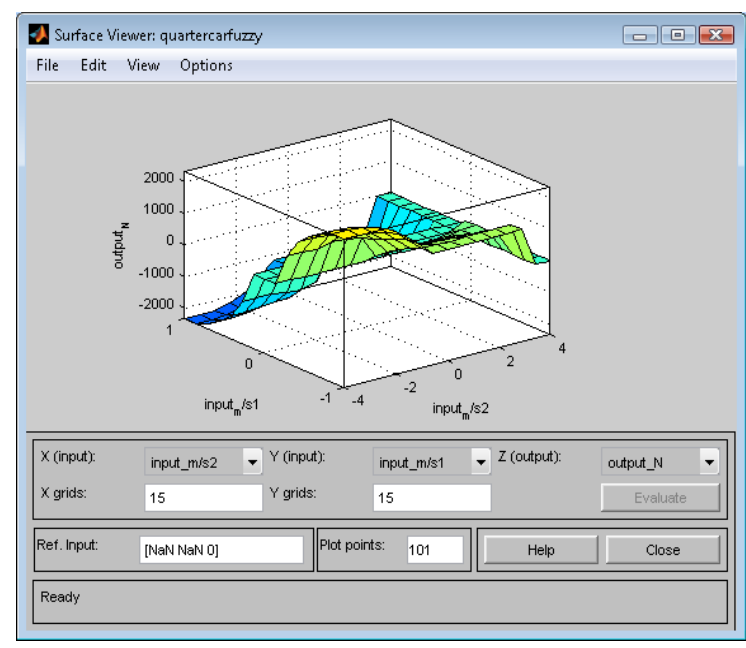

Fig. 12. Surface Viewer in in Matlab

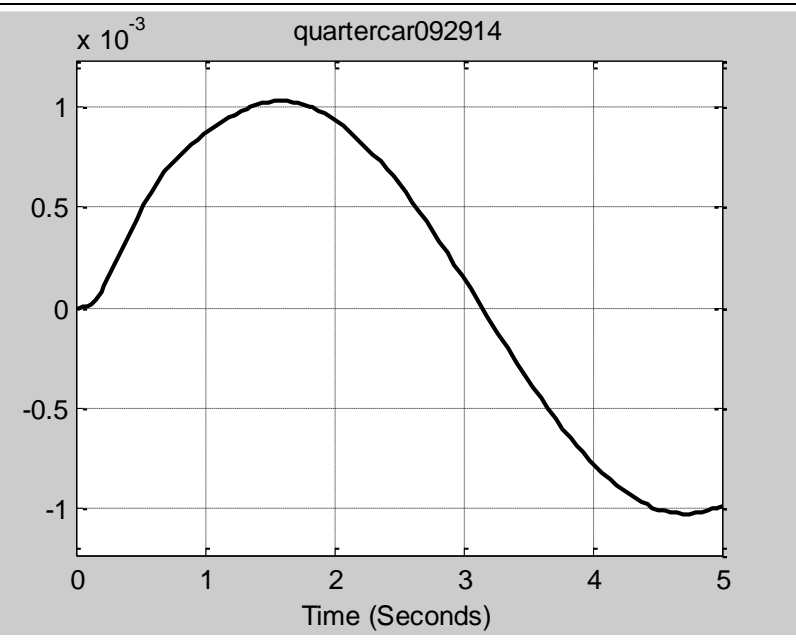

Fig. 13. Unsprung mass displacement for passive quarter car model 
Likaj, R.; Shala, A.; Bruqi, M. \& Bajrami, X.: Optimal Design and Analysis of Veh...

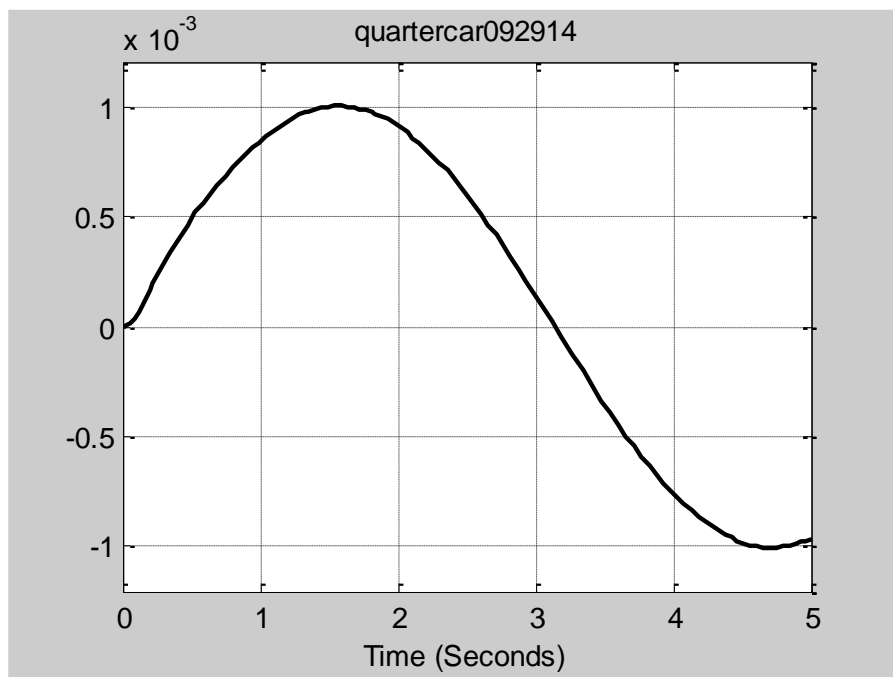

Fig. 14. Sprung mass displacement for passive quarter car model

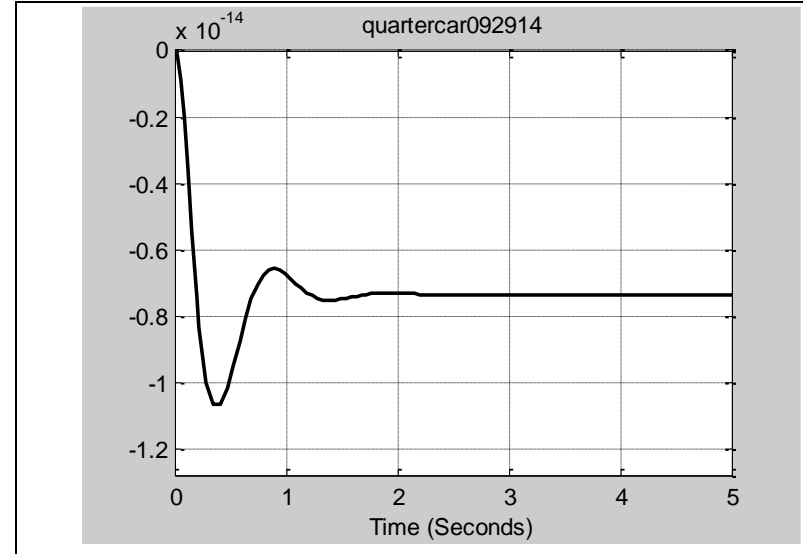

Fig. 15. Unsprung mass displacement active quarter car model

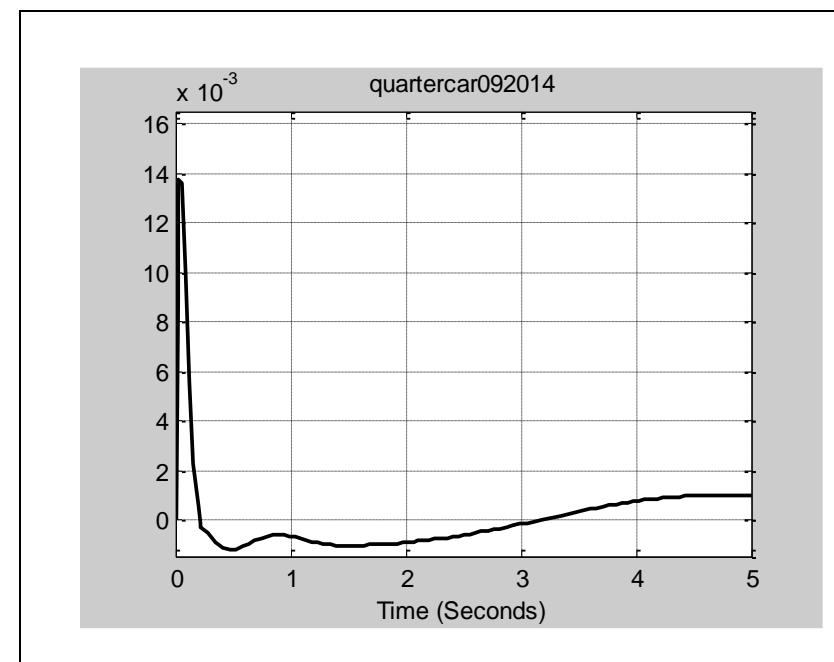

Fig. 17. Acceleration of unsprunged mass for passive quarter car model

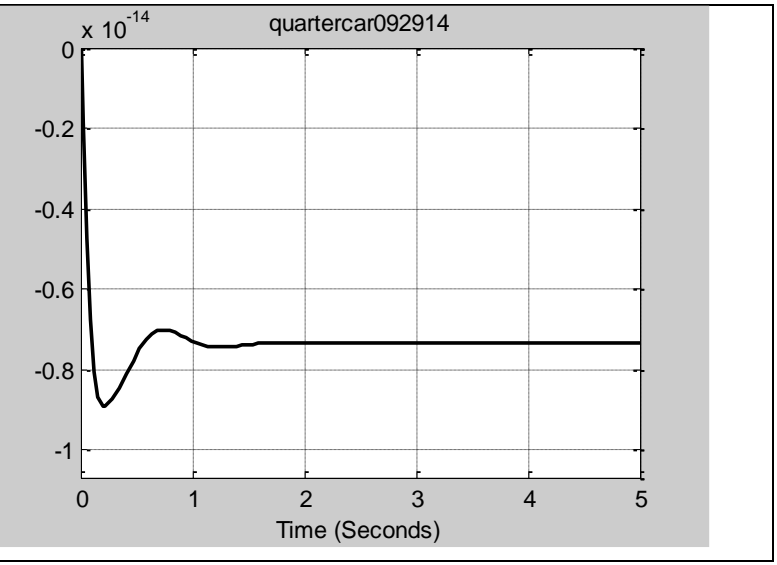

Fig. 16. Sprung mass displacement for active quarter car model

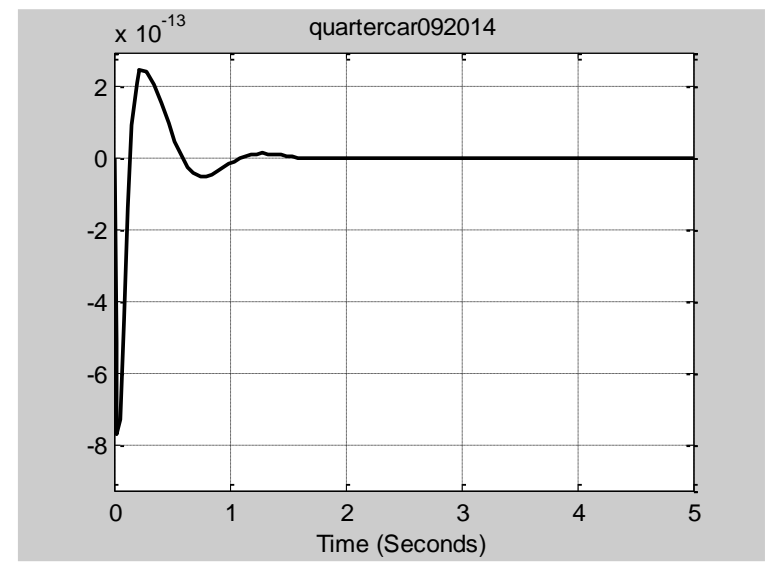

Fig. 18. Acceleration of unsprunged mass for active quarter car model 


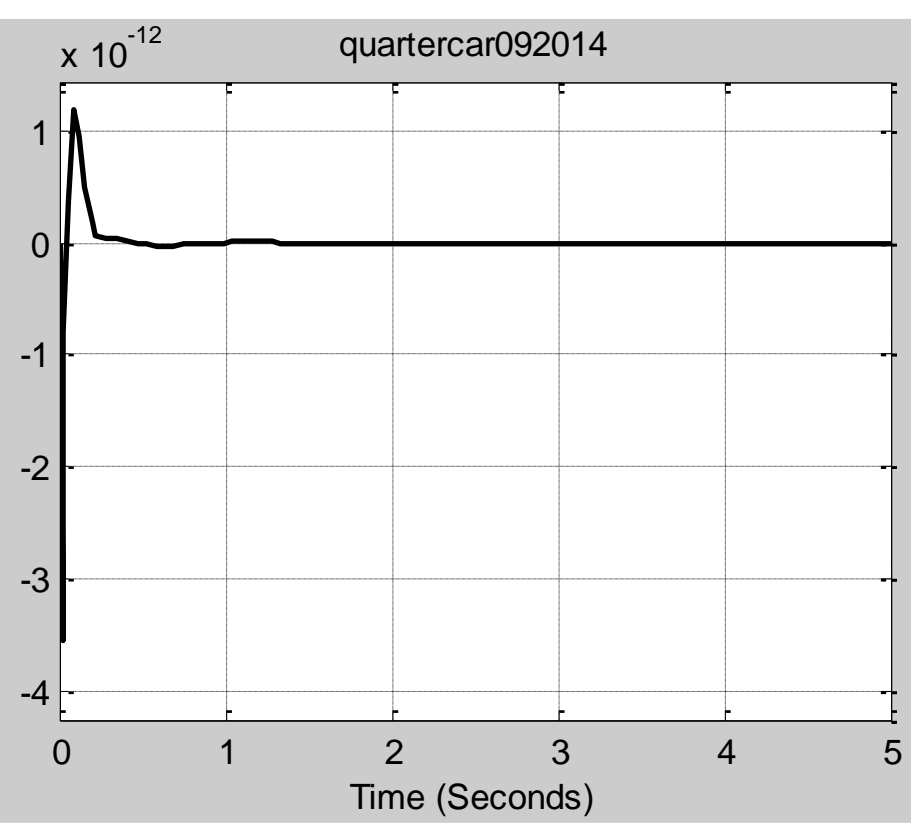

Fig. 19. Acceleration of sprunged mass for active quarter car model

\section{Conclusions}

A comparative study of two optimization algorithms (genetic algorithms, GAs and sequential quadratic programming, SQP), has been conducted through minimizing the vertical sprung mass acceleration subjected to a suspension working space and dynamic tire load.

By optimizing the design parameters compared with the original design, the sprung mass (body) acceleration decreases. The suspension working space and the dynamic tire load satisfy the specified design constraints. Based on the simulation results the optimum found by GAs at 19 generations, while by using the SQP the optimum is found after 51 iterations. As shown from the numerical simulation results in Fig. 4, the max amplitude of body displacement using optimized design variables is reduced for $9 \%$, while maximal amplitude of body acceleration is reduced around $22 \%$.

Numerical experiments reveal the fact that to improve vehicle ride quality and satisfy the specified suspension working space and relative dynamic tire load, different vehicle speed and road irregularity have different requirements on the design variables, in particular, the un-sprung mass.

From the parametric analysis it can be concluded that mass is a very sensitive parameter, and must be handled with special attention.

From the results of the natural frequencies obtained in both ways it can be concluded that the values are almost the same.

Active suspension systems using FL Controllers can reduce vertical accelerations, as shown in Fig. 19. This means, that the main properties; ride comfort and road holding were achieved for the quarter car model. For the design of an FLC, 
Likaj, R.; Shala, A.; Bruqi, M. \& Bajrami, X.: Optimal Design and Analysis of Veh...

an accurate vehicle model is not needed, but it's a very difficult task to express the knowledge and experience in terms of fuzzy logic.

Form the results of this study it became evident to us that the combination of MATLAB and SIMULINK represent a powerful tool on research of parametric analysis, optimisation and optimal control of vehicle suspension system.

Since the quarter car model is one the bests and represents the simplest model for the analysis of ride comfort, the same approach will be applied in our future research to analyse half car and full car vehicle suspension system

\section{References}

Cai,B.; Konik,D. (1993). Intelligent Vehicle Active Suspension Control using Fuzzy Logic, IFFAC World Congres, Vol.2, pp. 231-236

DOI:10.2507/daaam.scibook.2011.22

Jadlovska, A.; Katalinic, B.; Hrubina, K., \& Wessely, E. (2013). On Stability of Nonlinear Systems and Application to Apm Modeling, Chapter 11 in DAAAM International Scientific Book 2013, pp. 257-276, B. Katalinic \& Z. Tekic (Eds.), Published by DAAAM International, ISBN 978-3-901509-94-0, ISSN 1726-9687, Vienna, Austria , DOI: 10.2507/daaam.scibook.2013.11

Jadlovska, A.; Katalinic, B.;Hrubina, K.; Macurova, A. \& Wessely, E. (2011). Optimal Control of Nonlinear Systems with Constraints, Chapter 22 in DAAAM International Scientific Book 2011, pp. 265-282, B. Katalinic (Ed.), Published by DAAAM International, ISBN 978-3-901509-84-1, ISSN 1726-9687, Vienna, Austria Jadlovska, A.; Katalinic, B.;Hrubina; K.; Macurova, A.\& Wessely, E. (2012). Solution to the Problem Control of a Distributed Parameter Process, Chapter 15 in DAAAM International Scientific Book 2012, pp. 169-186, B. Katalinic (Ed.), Published by DAAAM International, ISBN 978-3-901509-86-5, ISSN 1726-9687, Vienna, Austria DOI:10.2507/daaam.scibook.2012.15

Likaj R.(2005). Fuzzy Logic Control on Nonlinear Vehicle Suspension System, Phd thesis, Prishtina, Kosovo

Likaj R.; Pajaziti A., (2002). Nonlinear and fuzzy Logic Control of Vehicle Suspensions, "Intelligent Manufacturing \& Automation: Learning from Nature" 13th International DAAAM Symposium; Annals Proceeding, ISBN 3-901509-29-1

Likaj R.; Shala A.; Bruqi M.; Qelaj M. (2009). Optimal Design of Quarter Car Vehicle Suspension System, Trends in the Development of Machinery and Associated Technology - ISSN 1840-4944; pp. 417-420; Livorno, Italy.

Likaj, R.; Geca, A.; Pajaziti, A. (2003). Parametric and sensitivity analysis of a vibratory vehicle model with 4 DOFs, MTeM 2003, Cluj Napoca, Romania

Likaj, R.; Geca, A.; Pajaziti, A.; Osmanaj S. (2005). Parametric and sensitivity analysis of four DOFs vehicle model, 4th DAAAM International Conference on Advanced Technologies for developing Countries, September 21-24, 2005, Slavonski Brod, Croatia 